\title{
Experimental Study on Temperature and Lateral Deformation of Rail at the Transition between Bridges and Tunnels
}

\author{
Jun Luo ${ }^{1, a}$, Zhiping Zeng ${ }^{2, b^{*}}$, Xiaobai Meng ${ }^{3, c}$ and Shanyi Song ${ }^{4, d}$ \\ 1, 2,3,4 School of Civil Engineering Central South University Changsha, China \\ a1964965318@qq.com, b996510155@qq.com, c269036993@qq.com, d458809515@qq.com
}

Keywords: Ballastless track; Continuously welded rail track; Lateral deformation of rail; Stability

\begin{abstract}
Research purposes: In recent years, according to on-site observation, it is found that CWR in ballastless track will produce lateral deformation in sporadic bending form. For high speed railway, it is easy to stimulate hunting motion of locomotive and rolling stock and has a great impact on driving stability, comfort and safety. Through carrying on monitoring experiment on lateral deformation of rail on ballastless track, the time-dependent property of lateral deformation of rail will be obtained, which attaches great significance to revealing the mechanism of lateral deformation of rail and ensuring the stability of the ballastless track lines, as well as safety and comfort of driving.
\end{abstract}

\section{Introduction}

Our country applies a large number of high-speed railway CWR in Ballastless track. The fastening system of ballastless track is directly connected with the concrete bed, compared with the ballast track, the stability of ballastless track is better and has enough vertical and horizontal resistance, which is generally considered to be away from track buckling accidents and not to check its stability [1-6]. And the ballastless track stability theory at home and abroad is short of systematic research [7]. But under special foundation conditions, such as the transition section between bridge and tunnel, due to be comprehensively affected by the train random loading, initial irregularity of rail and lateral expansion of bridge or other factors, the geometry state of the track changes relatively frequently, which plays a crucial role on the safety of the whole line and the quality of its operation.In August 2007, China Academy of Railway Sciences surveyed geometry state of the track(gauge and track alignment) of Jialing River Bridge, the Jiangjia bridge and Mu Yukou tunnel on the Suiyu line, three abnormal geometry state of the track was measured in the mouth of the tunnel and transition between road and bridge with the rail irregularity of the gauge deviation of 2.0 2.5mm and sporadic bending wavelength of $4 \mathrm{~m}[8,9]$. Study on basic characteristics and variation rules of track geometry state at transition section with scientific and comprehensive evaluation of track geometry state attach great scientific research value and engineering significance to revealing the sporadic bending phenomenon and the guidance of track maintenance for ballastless track CWR in high-speed railway.

\section{Summary of the Research}

The study carried out in $\mathrm{He} \mathrm{Fu}$ line, the transition between bridge and tunnel was selected to be tested continuously of the track deformation in long-term (April to July). A section of 10m long track was selected to be tested, 22 lateral displacement sensors and 6 temperature sensors were furnished in the same side of the line. The fixed bracket was used to fix the displacement sensors and acquisition instrument was applied to storage the monitoring data (storage every 30 minutes) and the solar panels and the storage battery power were supplied to ensure the normal work of the instrument. The number and positions of the measuring points are shown in Fig. 1. 


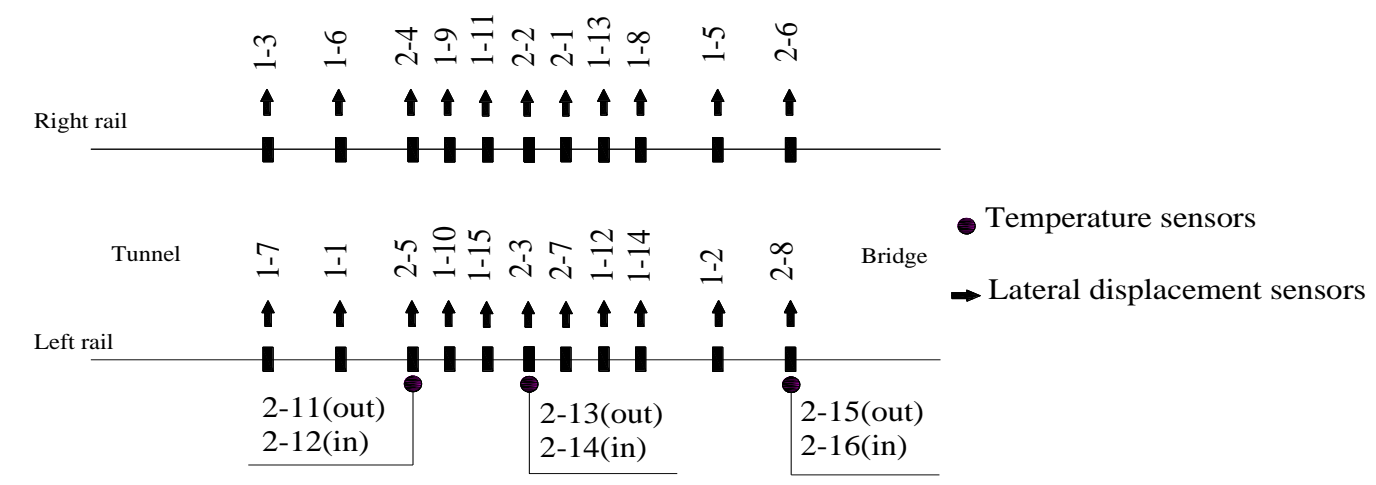

Figure 1. The number and positions of the measuring points

\section{Analysis of Rail Temperature}

Track buckling and rail expansion are closely related to the longitudinal temperature stress[10]. The temperature stress internally generated in CWR is stored in the form of energy in the rail, when there exists initial irregularity in the rail or track irregularity caused by lateral expansion of bridges in transition or other factors, the energy will transfer in the form of rail expansion or rail creep. The appearance of sporadic bending releases part of the temperature stress and the part of the stored energy is transmuted into deformation energy such as longitudinal crawling, buckling and deformation resistance of fasteners, etc. Therefore, the temperature stress is an important load effect of rail sporadic bending, and monitoring and analyzing the irregularity of rail temperature attach great importance.

The Curve of Rail Temperature. Six temperature sensors of three sets were furnished in the test section, which were used to measure the temperature inside and outside the rail waist of three rail points. Three sets of sensors from the tunnel to the bridge follow the order as group A:2-11 (out), 2-12 (in), group B: 2-13(out) and 2-14(in), group C: 2-15(out) and 2-16(in). The acquisition time lasted from April to July with a total of more than 5600 sets of temperature data. Fig. 2 depicts rail temperature curve with the change of the number of sampling of group A and group C (group B is similar).The figure shows that for the same measuring point, changes of the temperature of left and right side of rail waist are basically the same. It is known that the local installation temperature is $24 \pm 5^{\circ} \mathrm{C}$, and we found that the maximum temperature of group $\mathrm{A}, \mathrm{B}, \mathrm{C}$ were close to installation temperature, accounted for respectively $59 \%, 61 \%, 63 \%$ of the whole obtained data. Group C data collected in the tunnel mouth was greater affected by temperature, so it accounted for the highest proportion.

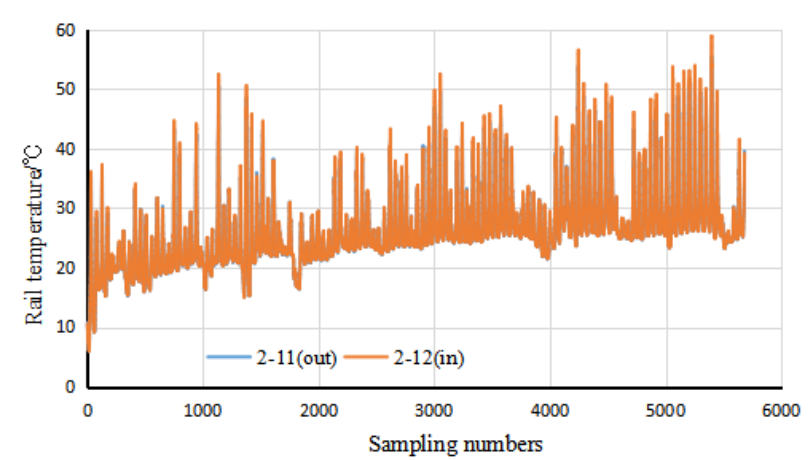

(a) Temperature measuring points of group $\mathrm{A}$

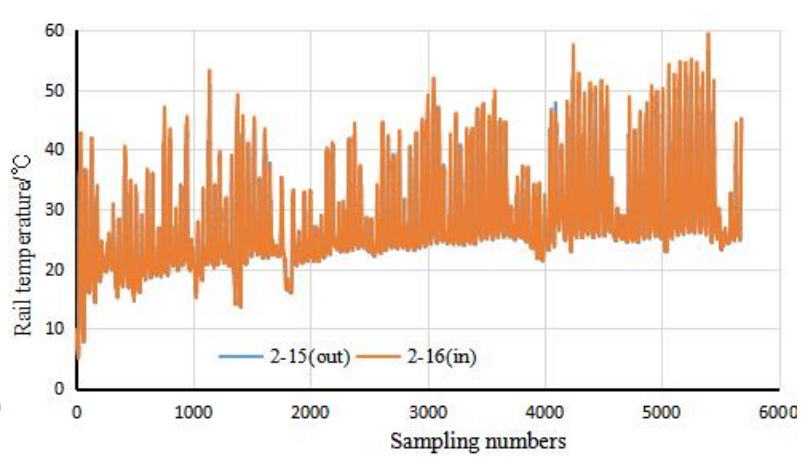

(b) Temperature measuring points of group $\mathrm{C}$

Figure 2. The curve of rail temperature

The Changing Regularity Of Daily Temperature Of The Rail. We selected a representative day of each month from April to July and the changing conditions of temperature of the three tested points (a total of 6 groups) at all times during a day were depicted in Fig. 3. From Fig. 1 we know that the order of the three tested points from the bridge to the tunnel is $2-13 / 14,2-15 / 16,2-11 / 12$. 
From Fig. 3, it's not difficult to find that the maximum temperature of the rail were $42.8^{\circ} \mathrm{C}, 45.6^{\circ} \mathrm{C}$, $51.9^{\circ} \mathrm{C}, 57.5^{\circ} \mathrm{C}$.

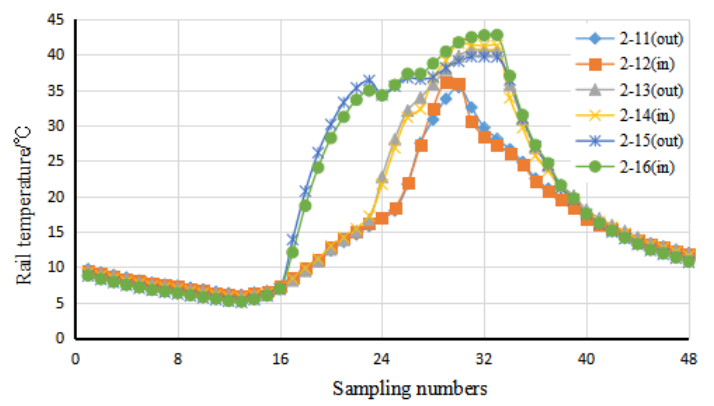

(a) The change of temperature in April $15^{\text {th }}$

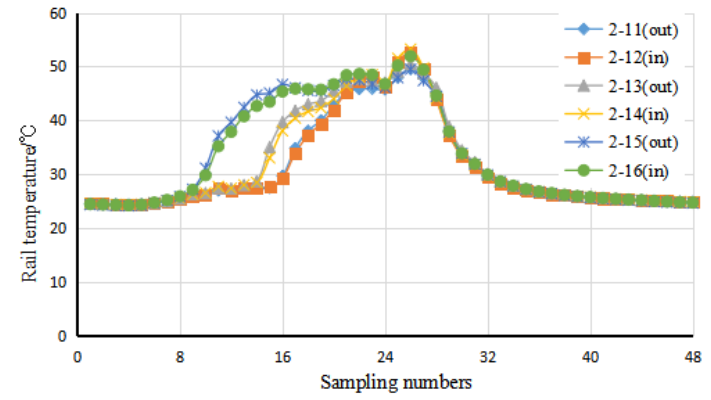

(c) The change of temperature in June $16^{\text {th }}$

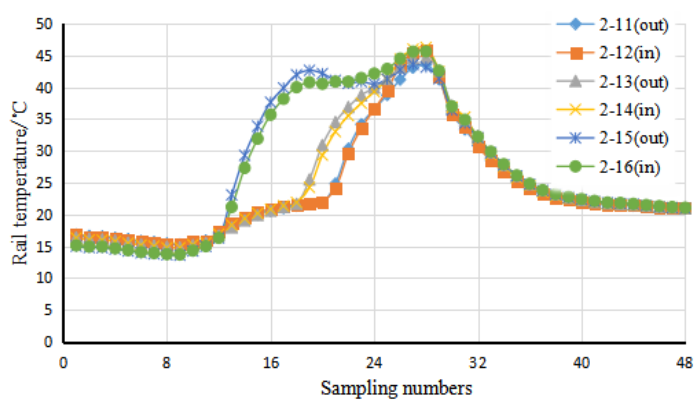

(b) The change of temperature in May $13^{\text {th }}$

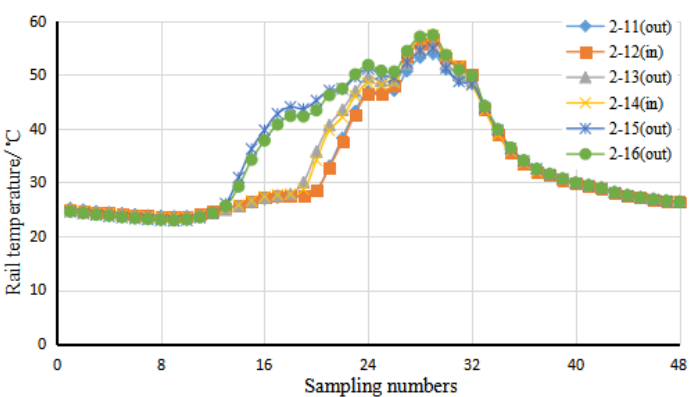

(d) The change of temperature in July $13^{\text {th }}$

Figure 3. The change of daily temperature of the rail

Due to the tunnel and sun angle effects, there existed a big difference between the 2-15/16 point and other points in the period of 7 a.m to 10 a.m. The biggest temperature difference was $20.7^{\circ} \mathrm{C}$ at 10:30a.m in April 15th. The biggest temperature difference was $21.5^{\circ} \mathrm{C}$ at 8:30a.m in May 13 th. The biggest temperature difference was $17.63^{\circ} \mathrm{C}$ at $7: 00 \mathrm{a} . \mathrm{m}$ in June 16 th. The biggest temperature difference was $16.73^{\circ} \mathrm{C}$ at $8: 45 \mathrm{a} . \mathrm{m}$ in July 13 th. It is obvious that there exist a temperature difference of $20^{\circ} \mathrm{C}$ in the range of $10 \mathrm{~m}$ of the rails at the transition between tunnel and bridge.

\section{Analysis of Regularity of Lateral Deformation of Rail}

The Curve of Rail Lateral Deformation. The regularity of rail lateral deformation is certain scattered, but there are tested points whose lateral deformation accumulate continuously. The points like this should be focused on specially, because they directly affect the geometry state of the track. Considering the length of this paper, only two points with cumulative characteristics showed in Fig. 4. The 1-1 point has the maximum cumulative deformation and the 2-3 point has the minimum cumulative deformation. The 2-3 point is furnished with temperature sensors and Fig. 4 (b) reflects the relationship between temperature and the fluctuation of rail deformation. It's known from Fig. 4 that the lateral deformation of rail shows periodic change with increase and decrease of the daily temperature, namely the Peaks and valleys of the two curves unit well. The maximum of daily fluctuations is no more than $0.25 \mathrm{~mm}$, and the deformation accompanied by accumulated deformation of $0.5 \sim 2 \mathrm{~mm}$ or so. 

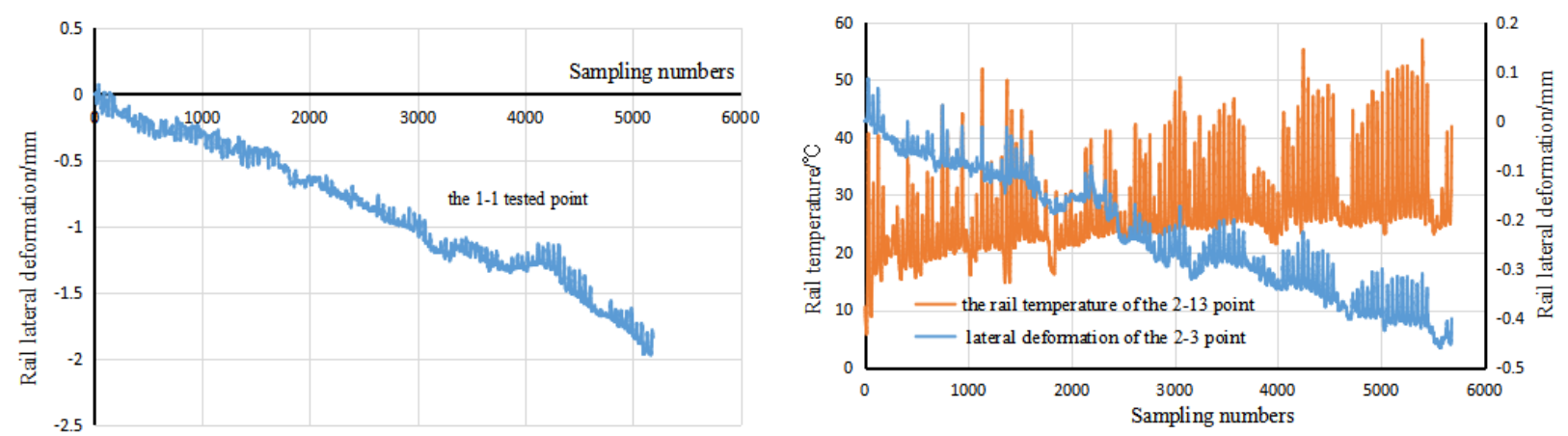

(a)The lateral deformation of the 1-1 tested point (b) The relationship between the lateral deformation and temperature

Figure 4. The curve of the change of rail daily temperature

The Curve of the Rail Sporadic Bending. In order to reflect the influence of rail lateral deformation on the track geometry, we connected the lateral deformation of the left and right rail at 6 moments within a day into the sporadic bending curve along the longitudinal line from the data acquired in July 31 th. The sporadic bending curves are shown in Fig. 5.

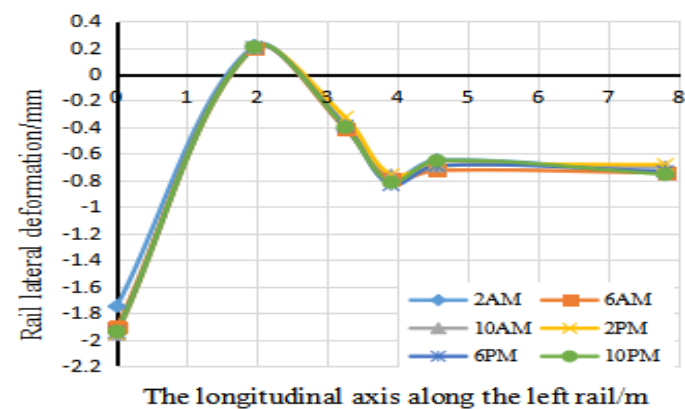

(a)The curve of the left rail sporadic bending in July 31 th

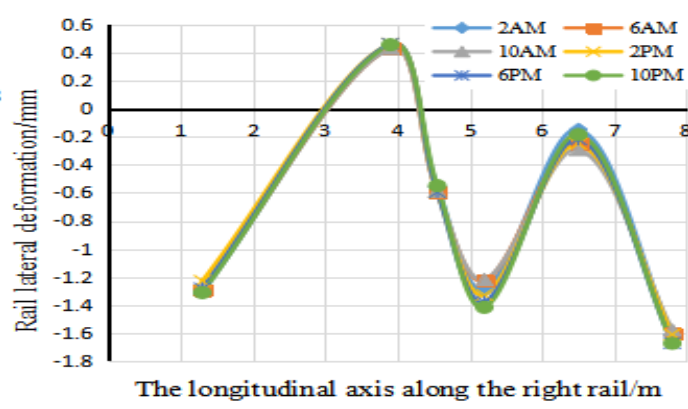

(b)The curve of the right rail sporadic bending in July 31 th

Figure 5. The curve of the rail sporadic bending

From the figure, it can be seen that rail displacement is mainly based on daily fluctuations at the beginning of the test, with the increase of the cumulative deformation, the curve of the rail sporadic bending tends to be steady when the daily fluctuations are quite small with respect to the cumulative deformation, which is shown in the figure that the curves are essentially coincident at each moment only with the growing trend of the amplitude of sporadic bending. Both of the left and right rail take on sporadic bending wavelength of $2.60 \mathrm{~m}$, which is 4 times than the fastener spacing.

\section{Conclusions}

(1)The lateral deformation of rail changes periodically with the increase and decrease of day temperature, the maximum of daily fluctuations is no more than $0.25 \mathrm{~mm}$;

(2)There is a temperature difference of $20^{\circ} \mathrm{C}$ in the range of $10 \mathrm{~m}$ of the rails, which will have influence on rail longitudinal creep;

(3)There exist measuring points with cumulative increase of the lateral deformation of the rail with the magnitude of $0.5 \mathrm{~mm} \sim 2 \mathrm{~mm}$ or so;

(4)Both of the left and right rails take on sporadic bending wavelength of 4 times than the fastener spacing.

\section{Acknowledgments}

The research described in this paper was financially supported by the Science and Technology Foundation of Nanchang Railway Bureau (Grant No. 201524); the Joint Fund of the National Natural Science Foundation of China (Grant No. U1434204); the National Natural Science 
Foundation of China (Grant No. 51378513); the Project of Innovation-driven Plan in Central South University (2015CXS014).

\section{References}

[1] Liu Dan, Li Peigang, Zhao Pingrui.Possibility discussion about overall instability of ballastless track [J]. Railway Engineering, 2011(10): 95-98.

[2] Liu Yong. Model Test of CWR Lateral Deformation of Ballastless Track [D]. Chendu: Southwest Jiaotong University Press, 2015.

[3]Tian Chunxiang.Research on Influence of Lateral Expansion of Bridge on the Deformation of the Ballastless Track [J]. Journal of Railway Engineering Society, 2015(3): 25-30.

[4] Luo Huapeng, Ma Xufeng, Wang Ping, etc.Effects of Initial Irregularity and Initial Bending Stacking on the Stability of Continuous Welded Rail[J]. Railway Standard Design, 2015(7): 40-44.

[5] Liu Feng. Finite Element Analysis on the Stability of Continuously Welded Rail Track[D]. Beijing: Beijing Jiaotong University, 2009.

[6] Liu Yong, Yang Rongshang.Research on the lateral deformation of element slab ballastless track Under the action of temperature force [J]. Railway Standard Design, 2015(1): 33-36.

[7] Yan Le. Research on the Lateral Stability of the CRTS I Slab Track [D]. Chendu: Southwest Jiaotong University Press, 2015.

[8] China Academy of Railway Sciences. Phenomena and countermeasures about sporadic bending of the rail of the experimental section of ballastless track on Suiyu line[R]. Beijing:China Academy of Railway Science,2007.

[9] Gao Liang. Research on the Key Technology of High-speed Railway CWR Track. [M]. Beijing: China Railway Publishing House, 2012.

[10]Xiao Jielin, Guo Likang, Liu Xueyi. Research on causes of Sporadic bending of Rail on the Ballastless Track [J]. Railway Engineering, 2009(2): 93-96. 